\title{
Characterization of in-vitro antioxidant, cytotoxic, thrombolytic and membrane stabilizing potential of different extracts of Cheilanthes tenuifolia and Stigmasterol isolation from n-hexane extract
}

\author{
Ananna Mahfuz ${ }^{1}$, Fayad Bin Abdus Salam ${ }^{1,2}$, Kanij Nahar Deepa ${ }^{1}$ and A. H. M. Nazmul Hasan ${ }^{1 *}$ (i)
}

\begin{abstract}
Background: Cheilanthes tenuifolia, a member of the Pteridaceae family, is an evergreen and small fern could be abundant of bioactive compounds. The present study was designed to investigate its many therapeutic properties and isolation of bioactive compounds from extracts of Cheilanthes tenuifolia.

Methods: The dried coarse plant powder was extracted with methanol and dried with rotary evaporator. The extract was further partitioned according to the increasing polarity: N-hexane $<$ chloroform $<$ ethyl-acetate $<$ methanol by modified Kupchan method. Then each extract fractions were investigated for their pharmacologic properties. Compounds were isolated from n-hexane fraction through column chromatography, followed by TLC and structure was determined by analysis of sample using ${ }^{1} \mathrm{H}-\mathrm{NMR}$ and matched with published phytochemistry report.

Results: Methanol fraction of Cheilanthes tenuifolia showed highest amount of total phenol content $(11.32 \pm 0.28$ $\mathrm{mg} / \mathrm{gm}$ GAE) followed by chloroform fraction $(9.71 \pm 0.31 \mathrm{mg} / \mathrm{gm}$ GAE) $>\mathrm{N}$-hexane fraction $(6.69 \pm 0.67 \mathrm{mg} / \mathrm{gm}$ GAE) > ethyl acetate fraction (5.36 $\pm 0.54 \mathrm{mg} / \mathrm{gm}$ GAE). The methanol fraction of Cheilanthes tenuifolia possessed highest amount $(7.11 \pm 0.52 \mathrm{mg} / \mathrm{gm}$ QE) of total flavonoid content. Our present study indicates that methanol extract was most potent $\left(\mathrm{IC}_{50}=9.926 \mu \mathrm{g} / \mathrm{ml}\right)$ inhibitor of DPPH free radicals. In brine shrimp lethality bio assay, all the extracts showed dose dependent increment of mortality and chloroform extract was found most cytotoxic $\left(L C_{50}=34.493 \mu \mathrm{g} / \mathrm{ml}\right)$ compared to other plant extracts. The chloroform fraction of Cheilanthes tenuifolia was most potent in terms of thrombolytic activity. A compound was isolated (CT-2) using column chromatography followed by TCL and PTLC (35\% pet ether in $\mathrm{CHCl}_{3}$ ) and analyzed by ${ }^{1} \mathrm{H}-\mathrm{NMR}$. The structure of stigmasterol was confirmed by comparing the ${ }^{1} \mathrm{H}-\mathrm{NMR}$ data with previously published phytochemistry report.
\end{abstract}

Conclusion: Cheilanthes tenuifolia could be a potential candidate for bioactive compounds and further studies on isolation and characterization of its bioactive compounds are highly required.

Keywords: Cheilanthes tenuifolia, Antioxidant, DPPH, Cytotoxicity, Stigmasterol

\footnotetext{
*Correspondence: nazmul_0155@yahoo.com

'Department of Pharamcy, University of Asia Pacific, 74/A, Green Road, Dhaka

1205, Bangladesh

Full list of author information is available at the end of the article
} 


\section{Introduction}

Plants, their whole parts or derivatives, most important natural resource are used for therapeutic benefits. In, Traditional Medicine (TM) System, plants are used as bulk ingredients which provides the basic health services to $80 \%$ of the world's population $[1,2]$. Medicinal plants have vast significance in human life as they are used as raw materials for the extraction of active constitution, pioneer for many synthetic drugs and as preparations for herbal and indigenous medicines [3]. Bangladesh has a long history of herbal medicines and affluent of medicinal plants among the South Asian countries [4]. It has been assumed that approximately 250 species of medicinal plants are employed for the preparation of traditional medicines which is the $50 \%$ of total species of plants grown in Bangladesh [5]. But, bulk of these plant kingdoms has not yet undergone extensive chemical, pharmacological, and toxicological research to investigate their bioactive compounds.

Cheilanthes tenuifolia, an evergreen and small fern of Pteridaceae family grows up to $70 \mathrm{~cm}$ in height [6]. It's usually found in open, moist shady and rocky mountain area, but sometimes also grown in moist shady habitat [7]. Ferns are naturally abundant of phytochemicals and many types of treasured flavonoids have been extracted from various ferns species. In prehistoric time, the rhizome juice of ferns was used to cure GI disorders as well as peptic ulcer and the rhizome paste of ferns for healing of cuts and wounds. It is reported that, traditionally, the juice is obtained from the leaves of the Cheilanthes tenuifolia, mixed with hot water and taken orally along with honey to treat throat pain [8], decoction of leaves and stems for healthy hair [9], tribes of North East India, use the extract of rhizome and roots as a general tonic [10]. Two flavonoids namely, rutin and quercetin have been isolated from ethyl acetate-soluble extract of Cheilanthes tenuifolia ( [6]. The main bio active compounds in C. tenuifolia fern are flavonoids and phenols yet; limited literature is available on the bioactive compounds of this fern species. The present study was designed to investigate its pharmacological activities in terms of antioxidant potential, cytotoxic activity, anti-inflammatory and, thrombolytic properties using in vitro model and to isolate bioactive compounds using column chromatography followed by TLC and NMR.

\section{Materials and methods}

\section{Collection of the plant and extraction process}

The whole plant of Cheilanthes tenuifolia was included in our present study. The plant was collected from the Jahangirnagar University campus, Savar, Dhaka and identified by a taxonomist of Department of Botany, Jahangirnagar University, Savar, Dhaka. The plant was sundried for 15 days and oven dried for 7 days at $40^{\circ} \mathrm{C}$ and then it was grinded into a powder. $1200 \mathrm{~g}$ of powder was taken and submersed into 6ltr of methanol and went through regular shaking for 14 days to prevent clump formation in order to ease of filtration. Then cotton filtration process was performed to get supernatant and rotary evaporator was used to dry the extract. Following the protocol established by Kupchan and developed by Wagenen et al. [11] solvent-solvent partitioning was performed to separate compounds in order to their polarity. At first, $5 \mathrm{~g}$ of crude extract was taken in a $500 \mathrm{~mL}$ beaker. In another beaker $90 \mathrm{~mL}$ of methanol was mixed with $10 \mathrm{~mL}$ of water. Then slowly the mixture was added to the extract to make an aqueous extract solution. Then the mixture was partitioned with $\mathrm{N}$-hexane, chloroform, ethyl-acetate and methanol. The extract solution was partitioned according to the increasing polarity: $\mathrm{N}$ hexane $<$ chloroform $<$ ethyl-acetate $<$ methanol in order to separate compounds according to the polarity present in the sample extract [11].

\section{Phytochemical screening}

Initial phytochemical screening was done to determine different phytochemical groups using standard procedures to reveal the presence of different bioactive compounds like flavonoids, alkaloids, glycerides, tannins, saponins, etc. [12].

\section{Antioxidant potential \\ Determination of total phenol content}

Folin-Ciocalteu Reagent (FCR) was used to determine total phenolic content of the plant extract. In the alkaline condition phenols ionize completely. When FolinCiocalteu reagent is used in this ionized phenolic solution the reagent will readily oxidize the phenols [13].1.0 $\mathrm{mL}$ of each plant extracts or standard of different concentration solution were taken in test tubes and $5 \mathrm{~mL}$ of Folin - ciocalteu (Diluted 10 fold) reagent solution was added to the test tubes. $4 \mathrm{~mL}$ of Sodium carbonate solution was added into the test tubes. The test tubes were incubated for $30 \mathrm{~min}$ at $20^{\circ} \mathrm{C}$ to complete the reaction (Only for standard). The test tube was incubated for $1 \mathrm{~h}$ at $20^{\circ} \mathrm{C}$ to complete the reaction (Only for extract). The absorbances of the solutions were measured at $765 \mathrm{~nm}$ using a spectrophotometer against blank. Standard curve was prepared using $0,50,100,150,200,250 \mu \mathrm{g} / \mathrm{ml} \mathrm{solu-}$ tions of Gallic acid and total phenol values was expressed in terms of Gallic acid equivalent, which is a common reference compound [14].

\section{Determination of flavonoid content}

Total flavonoid was determined using the aluminum chloride colorimetric method described by Wang and Jiao [15]. Quercetin is considered as a flavonol, one of the six subclasses of flavonoid compounds. Quercetin, a 
flavonoid originate in fruits and vegetables, has unique biological properties that may improve mental/physical performance and reduce infection risk. $1.0 \mathrm{ml}$ plant extracts $(200 \mu \mathrm{g} / \mathrm{ml})$ and standard (Quercetin) were added to $3 \mathrm{ml}$ of methanol and $200 \mu \mathrm{l}$ of $10 \%$ aluminium chloride solution, $200 \mu \mathrm{l}$ of $1 \mathrm{M}$ potassium acetate solution and $5.6 \mathrm{ml}$ of distilled water were added and then incubated for $30 \mathrm{~min}$ at room temperature to complete the reaction. Absorbance of the solution was measured at $415 \mathrm{~nm}$ using a spectrophotometer (Shimadzu UV PC1600) against blank. Total Flavonoid contents of the fractions were expressed as Quercetin equivalents (QE).

\section{Determination of total antioxidant capacity}

Phosphomolybdenum method of antioxidant capacity determination is based on the reduction of Mo (VI) to Mo (V) by the antioxidant compound and subsequent formation of a green phosphate/Mo (V) complex at acidic pH. Sample extracts $(0.3 \mathrm{~mL})$ was combined with $3 \mathrm{~mL}$ of reagent solution $(0.6 \mathrm{M}$ sulfuric acid, $28 \mathrm{mM}$ sodium phosphate and $4 \mathrm{mM}$ ammonium molybdate). The tubes were incubated at $95^{\circ} \mathrm{C}$ for $90 \mathrm{~min}$. After the mixture had cooled to room temperature, the absorbance of the solution was measured at $695 \mathrm{~nm}$ against blank. Total antioxidant capacity of the extract was measured from the equation obtained from the concentration versus optical density plot of ascorbic acid [16].

\section{DPPH free radical scavenging capacity}

The free radical scavenging activities (antioxidant capacity) of the plant extracts on the stable radical 1, 1diphenyl-2-picrylhydrazyl (DPPH) were estimated by the method of Brand-Williams [17]. The sample extract $(0.2$ $\mathrm{mL}$ ) was diluted with methanol and $2 \mathrm{~mL}$ of DPPH solution $(0.5 \mathrm{mM})$ was added. After $30 \mathrm{~min}$, the absorbance was measured at $517 \mathrm{~nm}$. The percentage of the DPPH radical scavenging was calculated from the measured absorbance data. Ascorbic acid was used as a reference or standard antioxidant in this assay method. The percentage (\%) inhibition activity was calculated from the following equation:

$$
\left\{\left(\mathrm{A}_{0}-\mathrm{A}_{1}\right) / \mathrm{A}_{0}\right\} \times 100
$$

Where, $A_{0}$ is the absorbance of the control, and $A_{1}$ is the absorbance of the extract/standard. Then \% inhibitions were plotted against log concentration and from the graph $\mathrm{IC}_{50}$ was calculated.

\section{In-vitro thrombolytic activity}

All extracts were undergone for thrombolytic activity and compared against standard streptokinase. $100 \mathrm{mg}$ of each extract was taken in separate vials and then dissolved using $10 \mathrm{ml}(10,000 \mu \mathrm{l})$ of distilled N-Hexane,
Chloroform, Ethyl acetate, Sterile Water and Methanol respectively. Commercially available lyophilized Streptokinase (1,500,000 I.U) was collected and $5 \mathrm{ml}$ sterile distilled water was added to it and mixed properly. The suspension formed was used as a stock solution from which $100 \mu \mathrm{l}(30,000$ I.U) was taken to be used for invitro thrombolysis assay. $5 \mathrm{ml}$ venous blood was drawn from healthy adult male volunteers with no haematological disorders or with any history of taking anticoagulant therapy. Aliquots of blood was then transferred to the previously weighed sterile Eppendorf tubes and was incubated at $37^{\circ} \mathrm{C}$ for $45 \mathrm{~min}$ to form clot. The serum was completely removed using sterile cotton bud after clot formation without disturbing the clot. Each Eppendorf tube was weighed again after removal of serum in order to determine the clot weight. $100 \mu \mathrm{l} \mathrm{solu-}$ tions of different fractionates along with crude extracts and pure compounds were added separately to each Eppendorf tube containing pre-weighed clot. One Eppendorf tube was contained with only $100 \mu \mathrm{l}$ of Streptokinase and another one was contained with only $100 \mu \mathrm{l}$ of sterile distilled water. These two tubes were considered as positive and negative control respectively. All the Eppendorf tubes were then incubated at $37^{\circ} \mathrm{C}$ in an incubator for about $90 \mathrm{~min}$ and then observed for clot lysis. The released fluid was removed from all Eppendorf tubes after incubation followed by weighing to determine the difference in weight after clot disruption. Difference obtained in weight taken before and after clot lysis was expressed as percentage of clot lysis [18].

\section{Membrane stabilizing potential}

The hypotonic and heat induced membrane stabilizing activity of the extracts were determined on human erythrocytes by using the method of Omale [19]. Membrane Stabilization method is a method that is usually employed to evaluate in-vitro anti-inflammatory activity of any possible drug substances. An adult human (male) of $70 \mathrm{~kg}$ with fair complexion and free from any kind of disease was subjected to collect RBC. Then the collected $\mathrm{RBC}$ was kept in a sterile test tube with an anticoagulant EDTA. A buffer was prepared using monosodium phosphate and its conjugate base, disodium phosphate having $\mathrm{pH}$. To prepare $500 \mathrm{ml}$ isotonic solution of $154 \mathrm{mM}$ strength, $4.5045 \mathrm{~g} \mathrm{NaCl}$ was added in sterile distilled water and mixed properly and for the preparation of $500 \mathrm{ml}$ hypotonic solution, having strength of $50 \mathrm{mM}$, $1.4625 \mathrm{~g} \mathrm{NaCl}$ was added in sterile distilled water. The collected blood was washed three times with isotonic solution $(154 \mathrm{mM} \mathrm{NaCl})$ in $10 \mathrm{mM}$ sodium phosphate buffer ( $\mathrm{pH} 7.4)$ through centrifuge action for $10 \mathrm{~min}$ at 3000 RPM to obtain the erythrocyte suspension. The test sample was contained with stock erythrocyte (RBC) suspension $(0.50 \mathrm{~mL})$ with $4.5 \mathrm{ml}$ of hypotonic solution (50 
$\mathrm{mMNaCl}$ ) in $10 \mathrm{mM}$ sodium phosphate buffer saline ( $\mathrm{pH}$ 7.4) along with either the different fractionates of methanolic extract $(2.0 \mathrm{mg} / \mathrm{mL})$ or Acetyl Salicylic Acid $(0.10 \mathrm{mg} / \mathrm{mL})$. In this study, Acetyl Salicylic Acid (ASA) was used as a reference standard. At room temperature the mixtures were incubated for $10 \mathrm{~min}$ then centrifuged for $10 \mathrm{~min}$ at $3000 \mathrm{~g}$ and finally the absorbance more specifically the optical density (O.D.) of the supernatant was measured at $540 \mathrm{~nm}$.

The percentage inhibition of either hemolysis or membrane stabilization was calculated using the following equation:

\%inhibition of hemolysis $($ Hypotonic solution Induced $)=100 \times \frac{\mathrm{OD}_{1}-\mathrm{OD}_{2}}{\mathrm{OD}_{3}}$

Where,

$\mathrm{OD}_{1}=$ Optical density of hypotonic-buffered saline solution alone (control) and $\mathrm{OD}_{2}=$ Optical density of test sample in hypotonic solution

The isotonic buffer containing $1.0 \mathrm{mg} / \mathrm{mL}$ of different extractives of stem bark of plant was placed in aliquot $(5 \mathrm{ml})$ into two duplicate sets of centrifuge tubes. The vehicle, in the same amount, was added to another tube as control. Erythrocyte suspension $(30 \mu \mathrm{L})$ was added to each tube and mixed gently by inversion. One pair of the tubes was incubated at $54^{\circ} \mathrm{C}$ for $20 \mathrm{~min}$ in a water bath. The other pair was maintained at $0-5^{\circ} \mathrm{C}$ in an ice bath. The reaction mixture was centrifuged for $3 \mathrm{~min}$ at $1300 \mathrm{rpm}$ and the absorbance i.e. the optical density (OD) of the supernatant was measured at $540 \mathrm{~nm}$. The percentage inhibition of hemolysis in tests was calculated according to the equation:

$$
\begin{aligned}
& \text { \%inhibition of hemolysis (Heat Induced) } \\
& \quad=100 \times\left(1-\frac{\mathrm{OD}_{2}-\mathrm{OD}_{1}}{\mathrm{OD}_{3}-\mathrm{OD}_{1}}\right)
\end{aligned}
$$

Here, $\mathrm{OD}_{1}=$ optical density $(\mathrm{OD})$ of the test sample unheated, $\mathrm{OD}_{2}=\mathrm{OD}$ of test sample heated, and $\mathrm{OD}_{3}=$ OD of control sample heated.

\section{Cytotoxic potential: brine shrimp lethality bioassay}

Brine shrimp lethality bioassay has been suggested for cytotoxic activities in plant extracts [20]. A simple zoological organism (Brine shrimp nauplii) is utilized in this method to conveniently monitor in vivo lethality. Brine shrimps (Artemia salina) were hatched using brine shrimp eggs in a conical shaped vessel $(1 \mathrm{~L})$, filled with sterile artificial seawater (prepared by using sea salt $38 \mathrm{~g} /$ $\mathrm{L}$ and adjusted $\mathrm{pH}$ 8.5) under constant aeration for $48 \mathrm{~h}$. Sample solutions are prepared by dissolving the test materials in pre-calculated amount of DMSO (Di-methyl sulphoxide). Ten nauplii are taken in vials containing 5 $\mathrm{ml}$ of simulated seawater. The samples of different concentrations are added. Survivors are counted after $24 \mathrm{~h}$.
The median lethal concentration, $\mathrm{LC}_{50}$ values of the test samples after $24 \mathrm{~h}$ are obtained by a plot of percentage of dead Shrimps against the logarithm of the sample concentration using Microsoft Excel. Vincristine sulphate is usually used as the reference cytotoxic drug.

\section{Isolation of Stigmasterol}

Bioactive compounds from plant extracts can be isolated by using column chromatography, TLC and PTLC and structure of obtained compounds can be elucidated by using NMR. The factors effective on separation process using column chromatography include molecular characteristics related to adsorption (liquid-solid), partition (liquid-solid), and affinity or differences among their molecular weights, polarity [21].

$10 \mathrm{~g}$ of silica was placed into the Erlenmeyer flask and $100 \%$ n-hexane was added to the Erlenmeyer flask containing the silica gel. Enough solvent was added to ensure that all the silica gel was properly solvated [22]. The $n$-hexane soluble fraction of the plant extract was loaded in the top of the column and eluted in test tubes with different solvent system composed of n-hexane, chloroform and ethyl acetate (from non polar to polar) in different proportions $(200 \mathrm{ml})$. Test tubes contained eluted sample from the column were placed in a test tube racks in sequential manner with proper labeling and numbering (From 1 to 229). Then the samples were run over a TLC plate with a specific solvent system as an initial screening to find out the test tubes that contained similar type of compounds. The value of similar retardation factor $\left(R_{f}\right)$, the contents of the test tubes were mixed together for further elution through TLC. TLC is the most applied method of isolation of bioactive compounds from plants [23]. After drying of the sample solution in the test tubes, samples were run over TLC plate using different solvent system composed of different faction of $n$-hexane, chloroform and ethyl acetate (in terms of polarity increment) and observed under UV lamp in long and short wavelength and spotted properly. Then the test tubes containing the mixture of sample of 95-117 were eluted with $35 \%$ pet ether in chloroform in preparative TLC, and compounds were identified under UV lamp in a short and large wavelength, eluted and coded as CT_2 and sent for ${ }^{1} \mathrm{H}$-NMR study to Bangladesh Council of Scientific and Industrial Research. Then the NMR data was matched with several known standard compounds NMR data from different literature and chemical library to find out the similarities and reveal the structure of our isolated compound.

\section{Results and discussion}

\section{Phytochemical groups}

Methanolic extract of whole plant of Cheilanthes tenuifolia was successively partitioned with $\mathrm{N}$-hexane, chloroform 
and ethyl-acetate according to modified Kupchan partition method [11]. Preliminary phytochemical analysis was performed for all the fractions showed the presence of alkaloids, glycosides, tannins, and steroids which are listed in Table 1.

The result of phytochemical screening showed that most of the compounds present in methanol fraction of the plant extract, specifically the presence of steroids in methanolic fraction was overwhelming. The presence of carbohydrates and glycosides were noticeable. Presence of tannin was not so much prominent in Cheilanthes tenuifolia plant. Presence of flavonoid was medium intensity in methanol extract and remained low intensity in other fractions. Glucosides and saponins were absent in all fractions of the plant extract. Presence of alkaloid was observed by using Hager's reagent, Wagner's reagent and Draggendroff's reagent.

\section{Total phenol content}

Gallic acid (GA) was taken as standard that provided a standard curve $\left(y=0.0043 x-0.0723, R^{2}=0.9803\right)$ to determine the total phenol content in different fractions. All experiments were performed three times and expressed as average \pm standard deviation (STD). In our study, methanol fraction of Cheilanthes tenuifolia showed highest amount of total phenol content $(11.32 \pm 0.28 \mathrm{mg} / \mathrm{gm}$ GAE) followed by chloroform fraction $(9.71 \pm 0.31 \mathrm{mg} / \mathrm{gm} \mathrm{GAE})>\mathrm{N}$-hexane fraction $(6.69 \pm 0.67 \mathrm{mg} / \mathrm{gm}$ GAE) $>$ ethyl acetate fraction (5.36 $\pm 0.54 \mathrm{mg} / \mathrm{gm} \mathrm{GAE})$, (Table 2).

\section{Total flavonoid content}

Aluminum chloride colorimetric method was used for flavonoids determination and Quercetin was used as standard that provided a standard curve to determine

Table 1 Phytochemical Analysis of Different Fractionates of Cheilanthes tenuifolia

\begin{tabular}{|c|c|c|c|c|}
\hline \multirow{2}{*}{$\begin{array}{l}\text { Phytochemical } \\
\text { Groups }\end{array}$} & \multicolumn{4}{|l|}{ Extracts } \\
\hline & Methanol & Chloroform & n-Hexane & Ethyl Acetate \\
\hline Carbohydrates & ++ & ++ & ++ & + \\
\hline Glycosides & ++ & - & - & ++ \\
\hline Glucosides & - & - & - & - \\
\hline Saponins & - & - & - & - \\
\hline Steroids & +++ & + & + & + \\
\hline Tannins & + & + & + & + \\
\hline Flavonoids & ++ & + & + & + \\
\hline \multicolumn{5}{|l|}{ Alkaloids } \\
\hline Hager's reagent & ++ & - & + & - \\
\hline Wagner's reagent & - & - & - & - \\
\hline Dragendroff's reagent & - & - & ++ & + \\
\hline
\end{tabular}

[Note: " + " indicates the presence and "-indicates the absence of any phytochemical group. " +++ " indicating strong intensity, " ++ " indicating medium intensity and " + " indicating weak intensity] the total flavonoid content in different fractions. Total flavonoid content of different extracts of the plant were calculated using the equation $\left(y=0.0094 x+0.0444, R^{2}=\right.$ $0.9905)$ obtained from reference standard quercetin and expressed as $\mathrm{mg} / \mathrm{gm}$ equivalent of quercetin (QE). The methanol fraction of Cheilanthes tenuifolia possess relatively highest amount $(7.11 \pm 0.52 \mathrm{mg} / \mathrm{gm} \mathrm{QE})$ of total flavonoid content among all of them. Flavonoid content in N-hexane remains in second highest position $(6.10 \pm$ $1.10 \mathrm{mg} / \mathrm{gm}$ QE) (Table 2).

\section{Total antioxidant capacity}

Ascorbic acid was taken as standard that provided a standard curve to determine the total antioxidant capacity in different fractions. Total antioxidant capacity of different extracts of the plant were calculated using the equation $\left(y=0.0077 x+0.176, R^{2}=0.9954\right)$ obtained from reference standard ascorbic acid and expressed as $\mathrm{mg} /$ gm equivalent of ascorbic acid (AAE) (Table 2). The ethyl acetate fraction of Cheilanthes tenuifolia possess relatively highest amount of total antioxidant capacity $(1.78 \pm 0.22 \mathrm{mg} / \mathrm{gm}$ AAE) among all of them. Antioxidant Capacity in $\mathrm{N}$-hexane remains in lowest position which is much poor and in methanol and chloroform fraction are very much analogous to each other. Our current study suggests that Cheilanthes tenuifolia possess very poor total antioxidant capacity.

\section{DPPH free radical scavenging capacity assay}

DPPH (1,1-diphenyl-2-picrylhydrazyl) was taken as reagent solution and ascorbic acid as standard that provided a standard curve to determine the scavenging capacity in different fractions. It is cleared from the result and graphical representation that Cheilanthes tenuifolia is a strong inhibitor of DPPH free radicle. Methanol fraction showed the highest potency to inhibit free radical DPPH $(9.926 \mu \mathrm{g} / \mathrm{ml})$. The capacity of chloroform and ethyl acetate fractions are also noteworthy $(98.24 \mu \mathrm{g} / \mathrm{ml}$ and $77.99 \mu \mathrm{g} / \mathrm{ml})$ and N-hexane showed minimal $(334.76 \mu \mathrm{g} / \mathrm{ml})$ activity to DPPH as increased $\mathrm{IC}_{50}$ value decreases inhibitory activity. All the extracts showed a dose dependent increment of inhibition of DPPH free radical (Fig. 1).

\section{Brine shrimp lethality bioassay}

Vincristine sulphate was used as the reference standard. Measured amount of the vincristine sulphate was dissolved in DMSO (dimethyl sulfoxide) to get an initial concentration of $50 \mu \mathrm{g} / \mathrm{ml}$ from which serial dilutions were made using DMSO to get $25 \mu \mathrm{g} / \mathrm{ml}, 12.5 \mu \mathrm{g} / \mathrm{ml}$, $5 \mu \mathrm{g} / \mathrm{ml}, 1 \mu \mathrm{g} / \mathrm{ml}, 0.5 \mu \mathrm{g} / \mathrm{ml}, 0.25 \mu \mathrm{g} / \mathrm{ml}, 0.125 \mu \mathrm{g} / \mathrm{ml}$ and $0.06 \mu \mathrm{g} / \mathrm{ml}$. A blank was taken as negative control group only contained DMSO. The $\mathrm{LC}_{50}$ values of the $\mathrm{N}$ hexane, chloroform, ethyl acetate and methanol soluble 
Table 2 Antioxidant and cytotoxic potential of different extracts of Cheilanthes tenuifolia

\begin{tabular}{|c|c|c|c|c|c|}
\hline Extracts & $\begin{array}{l}\text { Total Phenol Content, } \\
\text { mg/gm GAE }\end{array}$ & $\begin{array}{l}\text { Total Flavonoid } \\
\text { Content, mg/gm QE }\end{array}$ & $\begin{array}{l}\text { Total Antioxidant } \\
\text { Capacity, mg/gm AAE }\end{array}$ & $\begin{array}{l}\text { DPPH Free Radical Scavenging } \\
\text { Potential, } \mathrm{I}_{50} \mathrm{\mu g} / \mathrm{ml}\end{array}$ & $\begin{array}{l}\text { Cytotoxic Potential, } \\
\mathrm{LC}_{50} \mathrm{\mu g} / \mathrm{ml}\end{array}$ \\
\hline $\begin{array}{l}\text { Methanol } \\
\text { Extract }\end{array}$ & $11.32 \pm 0.28^{b}$ & $7.11 \pm 0.52$ & $1.15 \pm 0.10^{a, b}$ & $9.926^{a}$ & 751.169 \\
\hline $\begin{array}{l}\text { Chloroform } \\
\text { Extract }\end{array}$ & $9.71 \pm 0.31^{b}$ & $4.35 \pm 0.24$ & $1.41 \pm 0.29^{\mathrm{a}, \mathrm{b}}$ & $98.24^{a}$ & 34.49 \\
\hline $\begin{array}{l}\text { Ethyl-Acetate } \\
\text { Extract }\end{array}$ & $5.36 \pm 0.54^{b}$ & $4.27 \pm 0.34$ & $0.26 \pm 0.18^{a, b}$ & $334.76^{\mathrm{a}}$ & 66.235 \\
\hline $\begin{array}{l}\mathrm{N} \text {-Hexane } \\
\text { Extract }\end{array}$ & $6.69 \pm 0.67^{b}$ & $6.10 \pm 1.10$ & $1.78 \pm 0.22^{\mathrm{a}, \mathrm{b}}$ & $77.99^{\mathrm{a}}$ & 205.984 \\
\hline Ascorbic Acid & - & - & - & 3.978 & - \\
\hline Vincristine & - & - & - & & 2.254 \\
\hline
\end{tabular}

[Values are represented as mean \pm SD. t-test of two equal variance was done to analyze the data sets. Values in same column with different superscripts are significantly different from another, $p<0.05]$

extracts were $205.984 \mu \mathrm{g} / \mathrm{ml}, 34.493 \mu \mathrm{g} / \mathrm{ml}, 66.235 \mu \mathrm{g} / \mathrm{ml}$ and $751.169 \mu \mathrm{g} / \mathrm{ml}$ respectively on shrimp nauplii versus the $\mathrm{LC}_{50}$ of vincristine sulfate was $2.254 \mu \mathrm{g} / \mathrm{ml}$. According to this study, chloroform extract was found to be most cytotoxic followed by ethyl acetate extract.

\section{In-vitro thrombolytic activity}

According to our present study, addition of $100 \mu \mathrm{l}$ streptokinase (SK) for fibrinolytic drugs as a positive control (30,000 IU) to the clots and subsequent incubation for $90 \mathrm{~min}$ at $37{ }^{\circ} \mathrm{C}$ showed $67.015 \%$ lysis. On the other hand sterile distilled water, a negative control exhibited a negligible percentage of lysis of clot $8.511 \%$, ethyl acetate extract $31.594 \%$, N-hexane fraction $12.100 \%$, methanol fraction $17.006 \%$ and chloroform fraction $41.261 \%$ showed lysis of clot respectively. Chloroform fraction was found most potent thrombolytic potential compared to standard SK.
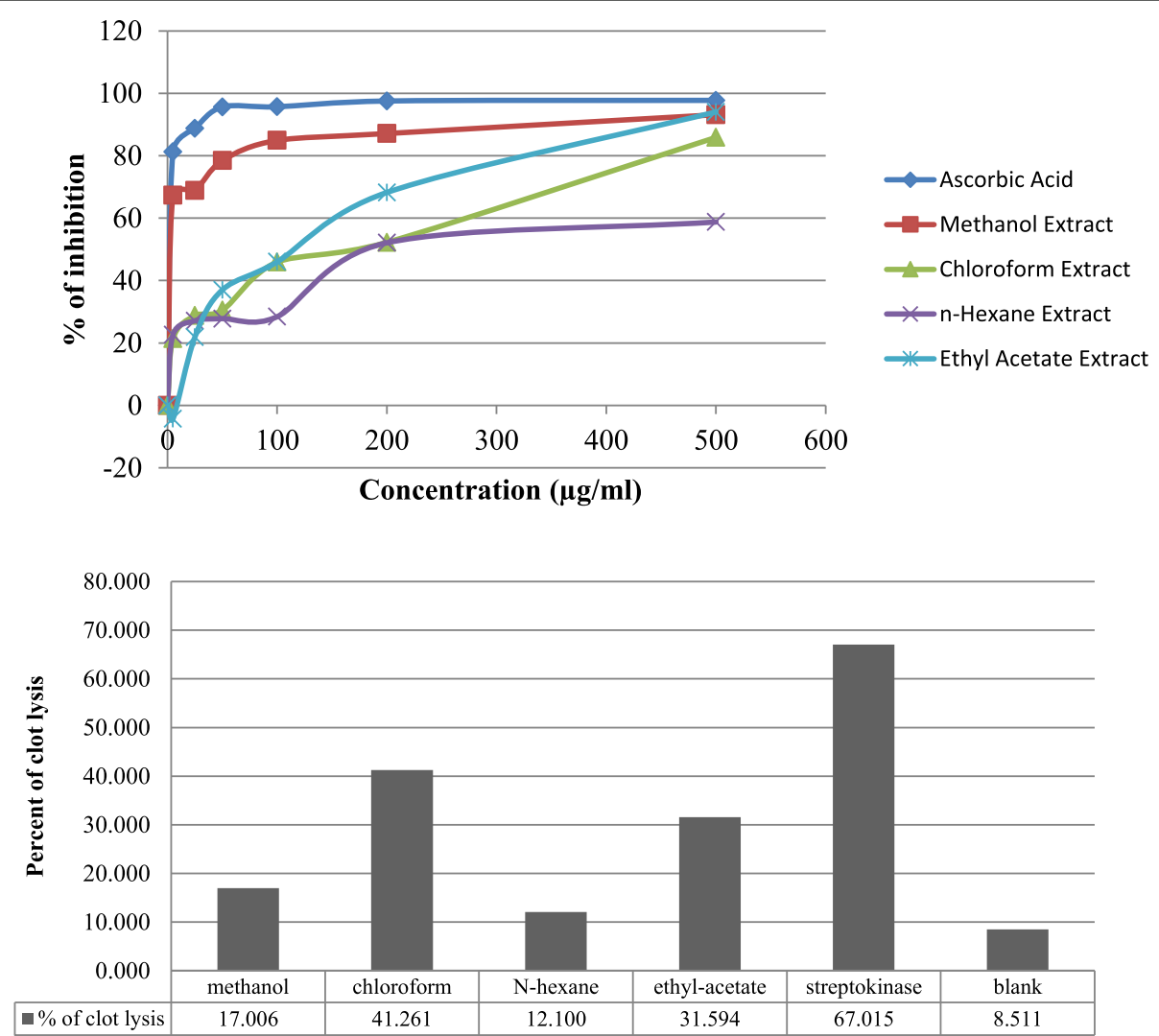

Fig. 1 Comparative percent of inhibition of DPPH free radicals and thrombolytic activity of different extracts of Cheilanthes tenuifolia 


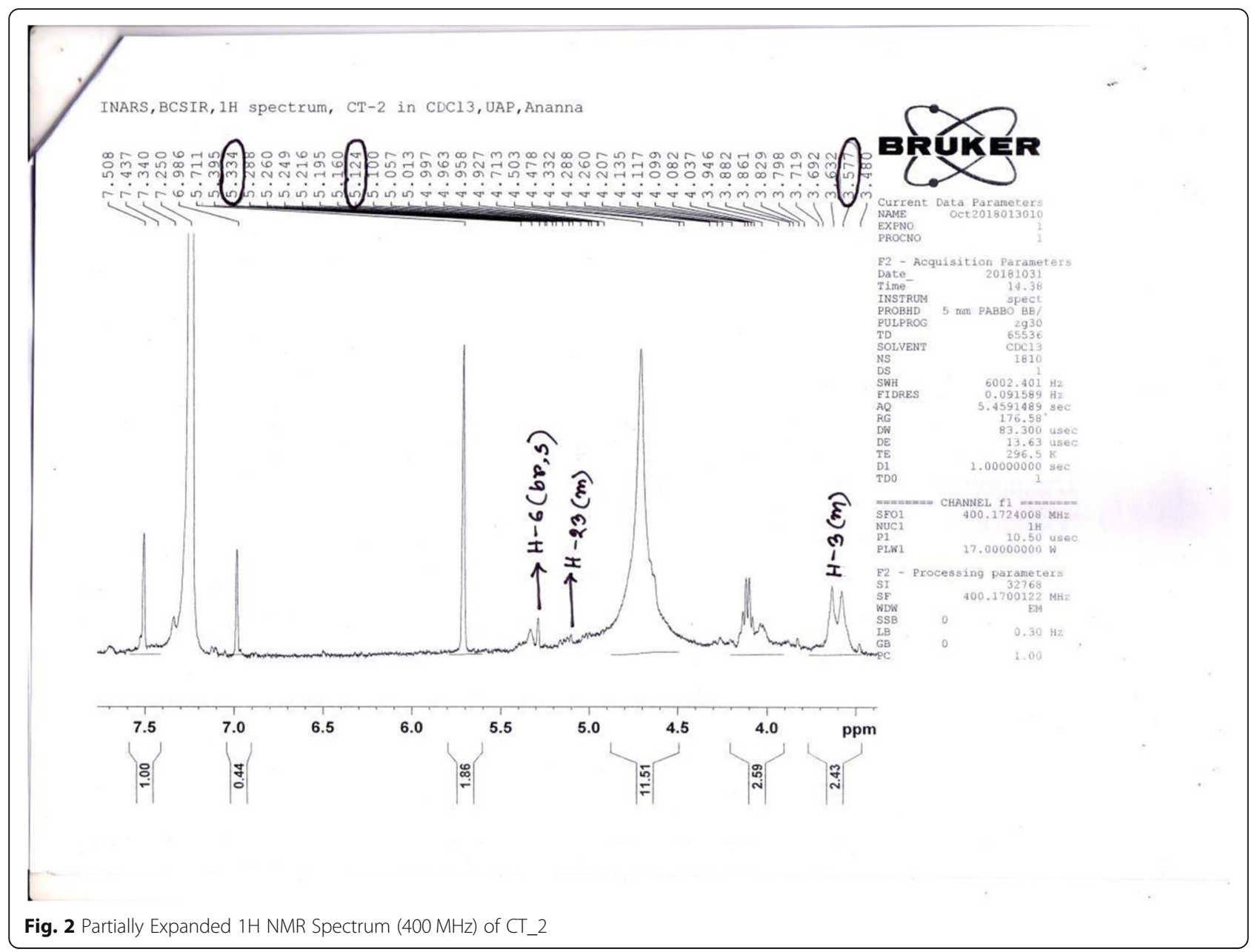

\section{Membrane stabilizing activity}

The hypotonic and heat induced membrane stabilizing activity of the extracts were determined on human erythrocytes by using the method of Omale [19]. Acetyl salicylic acid (ASA, synthetic aspirin) was taken as standard. Results of membrane stabilizing potential (hypotonic solution induced and heat induced hemolysis) of different extracts is summarized in (Table 3 ).

\section{Isolation of Stigmasterol from Cheilanthes tenuifolia}

After performing silica column chromatography, TLC and PTLC technique, several possible compounds were isolated through elution from $n$-Hexane fraction and sample studied for ${ }^{1} \mathrm{H}-\mathrm{NMR}$ spectroscopy. According to the NMR report, a prominent compound had been identified coded as CT_2. The ${ }^{1} \mathrm{H}$ NMR spectrum $(400 \mathrm{MHz}$, $\mathrm{CDCl}_{3}$ ) of CT 2 (Fig. 2) revealed doublets at $\delta 1.011(\mathrm{~J}=$ $7.6 \mathrm{~Hz}), \delta 0.830(\mathrm{~J}=6 \mathrm{~Hz}), \delta 0.793(\mathrm{~J}=7.2 \mathrm{~Hz})$ the positions of which are indicative of $\mathrm{H}-21, \mathrm{H}-27$ and $\mathrm{H}-26$ protons in the structure. The spectrum also revealed a triplet at $\delta 0.811$ which indicates $\mathrm{H}-29$ proton. and singlets at $\delta 0.696, \delta 0.944, \delta 0.696, \delta 5.334, \delta 0.944$ and $\delta$ 0.696 which are identical to $\mathrm{H}-6$ and $\mathrm{H}-18$ proton and multiplate at $\delta 3.57, \delta 5.12$ that revealed $\mathrm{H}-23$ and $\mathrm{H}-3$ proton. All these signals indicated that CT_2 contains a compound of sterol moiety and in comparison; with the

Table 3 Membrane stabilizing potential of different extracts of Cheilanthes tenuifolia

\begin{tabular}{llll}
\hline Extracts & Concentration & Percent of inhibiton of hypotonic solution induced hemolysis & Percent of inhibiton of heat induced hemolysis \\
\hline Methanol & $1 \mathrm{mg} / \mathrm{mL}$ & 2.974 & 8.625 \\
N-hexane & $1 \mathrm{mg} / \mathrm{mL}$ & 73.792 & 46.269 \\
Ethyl acetate & $1 \mathrm{mg} / \mathrm{mL}$ & 35.130 & 69.270 \\
Chloroform & $1 \mathrm{mg} / \mathrm{mL}$ & 3.346 & 59.801 \\
Acetyl Salicylic Acid & $0.10 \mathrm{mg} / \mathrm{mL}$ & 63.941 & 52.941 \\
\hline
\end{tabular}


published data of stigmasterol it showed that the sterol moiety might be stigmasterol (Fig. 3). The ${ }^{1} \mathrm{H}$ NMR data was compared to those of stigmasterol described by Chaturvedula et al [24] and it was found to be identical that is shown in Table 4.

\section{Discussion}

In our study we have extracted the plant with methanol and primary phytochemical screening of Cheilanthes tenuifolia shown in Table 1 that the plant fractions are enriched with steroid compounds and contain flavonoids about medium intensity. The other compounds like carbohydrates, glycosides, tannins, and alkaloids remain as medium intensity in the plant. Secondary metabolites of plant are mainly responsible for different pharmacological properties and their therapeutic benefits. Free radicals generated by metabolic reactions and/or exogenous chemicals are responsible for oxidation of biomolecules like nucleic acids, lipids, proteins, etc. These free radicals are responsible for oxidative stress and various degenerative diseases in human body. Antioxidants have inhibitory capacity to oxidative stress induce cellular damage and their main mechanism underlying this property is to scavenge free radicals due to their redox capacity $[12,13]$. Phenolic compounds from plant act as good scavengers of free radicals [25]. Polyphenols, which are highly reactive as hydrogen or electron donors, can stabilize or delocalize the unpaired electron (chain breaking function) and chelate metal ions [16]. Our recent study revealed that Cheilanthes tenuifolia is enriched with flavonoid content (Table 2). The ability of the plant extracts to reduce Phosphate/Mo (IV) to Phosphate $/ \mathrm{Mo}(\mathrm{V})$ is the basis of estimation of their total antioxidant capacity. It is a quantative method, since the antioxidant potential is expressed as the number of equivalent of ascorbic acid and there is highly positive relationship between phenolic compounds and antioxidant activity. By using ascorbic acid as determinant of

Table $4{ }^{1} \mathrm{H}$ NMR $\left(400 \mathrm{MHz}_{1} \mathrm{CDCl}_{3}\right)$ Spectral Data of $\mathrm{CT} 2$ and Stigmasterol in $\mathrm{CDCl}_{3}$

\begin{tabular}{lll}
\hline Position & \multicolumn{2}{l}{$\delta \mathrm{H}$ in ppm in $\mathrm{CDCl}_{3}$} \\
\cline { 2 - 3 } & Isolated compound $(\mathrm{CT} 2)$ & Stigmasterol [24] \\
\hline 3 & $3.57(3 \mathrm{H}, \mathrm{m})$ & $3.52(\mathrm{~m})$ \\
6 & $5.334(\mathrm{br}, \mathrm{s})$ & $5.357(\mathrm{br} \mathrm{s})$ \\
18 & $0.696(3 \mathrm{H}, \mathrm{s})$ & $0.699(3 \mathrm{H}, \mathrm{s})$ \\
21 & $1.011(\mathrm{~d}, \mathrm{~J}=7.6 \mathrm{~Hz})$ & $1.02(\mathrm{~d}, 7.5)$ \\
23 & $5.124(\mathrm{~m})$ & $5.14 \mathrm{~m}, 1 \mathrm{H}$ \\
26 & $0.793(\mathrm{~d}, \mathrm{~J}=7.2 \mathrm{~Hz})$ & $0.795(\mathrm{~d}, 6.5 \mathrm{~Hz})$ \\
27 & $0.830(\mathrm{~d}, \mathrm{~J}=6 \mathrm{~Hz})$ & $0.846(\mathrm{~d}, 6.5 \mathrm{~Hz})$ \\
29 & $0.811(\mathrm{t})$ & $0.804(\mathrm{t}, 7.5 \mathrm{~Hz})$ \\
\hline
\end{tabular}

On the basis of NMR data, the isolated compound was confirmed as stigmasterol and structure of stigmasterol is shown in (Fig. 3) antioxidant capacity, the observed result was not so indicative but only this result cannot ensure about poor antioxidant activity of Cheilanthes tenuifolia. There are many methods to decide in-vitro antioxidant activities and DPPH scavenging activity is one of them. DPPH receives an electron donated by antioxidant compounds and become decolorized, which can be quantitatively measured from the changes in absorbance [16]. In our present study, we observed that, the investigated plant extracts possess good DPPH free radical scavenging potential.

The process of breaking down or lysis of blood clots within the blood vessel through pharmacological means is known as thrombolysis [26]. In the present study, different crude methanolic extract fractions of Cheilanthes tenuifolia were evaluated for their possible thrombolytic activities. The thrombolytic activities of the extract were evaluated against reference standard streptokinase. The present study revealed that the chloroform fraction of Cheilanthes tenuifolia showed highest thrombolytic potential. Heat-induced hemolysis and membrane stabilization by hypotonic solution were used to determine the anti-inflammatory potential of the plant extracts. As the erythrocyte membrane is similar to lysosomal membrane and drug effects on erythrocyte stabilization could likely be to the stabilization of lysosomal membrane [27]. The hypotonic and heat induced membrane stabilizing potential of the extracts were determined on human erythrocytes by using the method of Omale [19]. In this study, the extracts of Cheilanthes tenuifolia were subjected for membrane stabilizing activity by using human erythrocyte and the results were compared with acetyl salicylic acid (ASA), a standard antiinflammatory drug. In the light of the results, we can conclude that the plant extract of Cheilanthes tenuifolia possesses moderate membrane stabilizing activity. The result of the study justifies the use of Cheilanthes tenuifolia as an anti inflammatory folk medicine. To determine the cytotoxicity of plant extract, brine shrimp lethality assay is an important parameter by observing the capability of extract to kill a laboratory cultured larvae (nauplii). The nauplii were exposed to different concentrations of plant extract for $24 \mathrm{~h}$. The morbidities of nauplii will be calculated to determine the effectiveness of the extract as cytotoxic agent [28]. It has been established as a safe and practical method for determination of bioactivities of natural product extracts as well as synthetic and semi-synthetic compounds [26]. In our present study, fractions from methanol, chloroform, ethyl acetate and $\mathrm{N}$-hexane of plant extract showed positive results which indicate that the test samples had cytotoxic potential.

Bioactive compounds can be isolated from plants by using column chromatography, TLC and PTLC and structure of obtained compounds will be elucidated by 


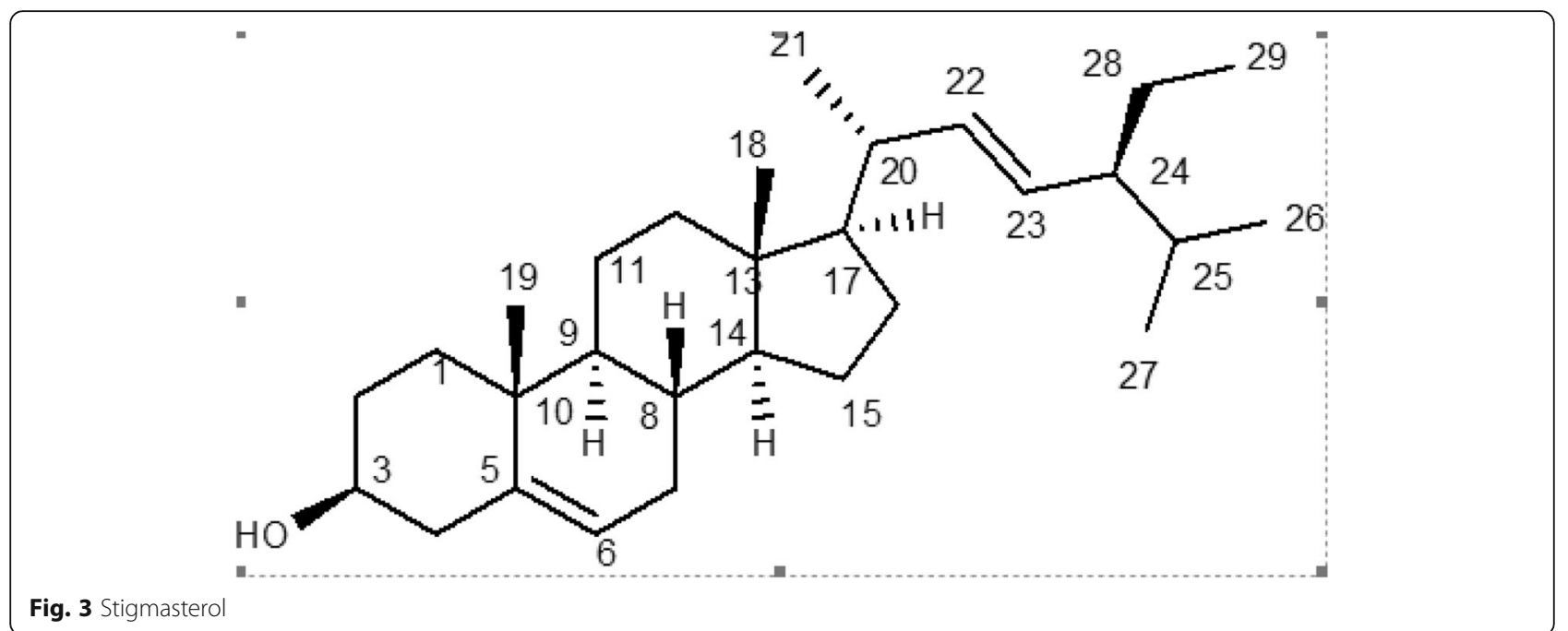

using ${ }^{1} \mathrm{H}$ and ${ }^{13} \mathrm{C}$ NMR [29]. In present study, after performing silica column chromatographic technique and TLC technique, several possible compounds were isolated through elution from n-Hexane fraction. The isolated pure compounds were then characterized by extensive spectroscopic studies as well as by comparison with previously isolated compounds reported in different phyto chemistry report. By examined the samples in ${ }^{1} \mathrm{H}$ NMR we have enabled to isolate a chemical compound $\left(\mathrm{CT}_{-}\right.$2) similar to stigmasterol. Stigmasterol is a phytosterols well spread in plants and animals as well as fungi, and has structural similarity to cholesterol.

\section{Conclusion}

The results from this study indicate that the extracts of Cheilanthes tenuifolia possess good to moderate antioxidant activities and good brine shrimp lethality. Polyphenolic compounds, flavonoids and various other phytochemicals existing in the plant may be responsible for its antioxidant and cytotoxic potential and can be a great source of natural antioxidant and new cytotoxic compound. It is also obvious that the differences of activity in different extracts. The extracts of Cheilanthes tenuifolia of different polarities showed significant in vitro thrombolytic and membrane stabilizing activities. It may be assumed that these extracts can be considered as good source of thrombolytic and membrane stabilizing agents due to presence of high number of flavonoids. However, further studies are suggested to understand the underlying mechanism of the observed activities of Cheilanthes tenuifolia.

\section{Acknowledgements}

Authors are thankful to Phytochemistry Research Laboratory, Department of Pharmacy of University of Asia Pacific, to provide necessary laboratory support and BCSIR (Bangladesh Council of Scientific and Industrial Research) for NMR study of the samples.
Authors' contributions

All the authors are equally participated in this research work. Author $\mathrm{AHMNH}$ and FBAS were involved in design of the study, AM, FBAS, KND and AHMNH were involved in the laboratory work. Author AHMNH acted as supervisor of this research work and KND finally reviewed and edited the manuscript. All authors read and approved the final manuscript.

\section{Funding}

The authors received no external funding for this research.

Availability of data and materials

All the data and materials are preserved by the authors and are ready to provide at any stage if any question arise.

\section{Ethics approval}

This study was approved by ethical committee (Ref: UAP/Pharm_ETA: 05_032018) of the Department of Pharmacy, University of Asia Pacific. No animals were used/harmed in this experiment. Written informed consent was obtained from the volunteers from whom blood samples were withdrawn. Blood pressure was measured and history of taking any medications like antiplatelet/corticosteroid were taken and excluded if anyone had history of this.

\section{Consent for publication}

All the authors reviewed the manuscript and provide consent for publication.

\section{Competing interests}

The authors declare that they have no competing interests.

\section{Author details}

'Department of Pharamcy, University of Asia Pacific, 74/A, Green Road, Dhaka 1205, Bangladesh. ${ }^{2}$ Pharmacy Discipline, Khulna University, Khulna 9208, Bangladesh.

Received: 13 May 2019 Accepted: 6 November 2019

Published online: 02 December 2019

\section{References}

1. Karthik V, Raju K, Ayyanar M, Gowrishankar K, Sekar T. Ethnomedicinal uses of Pteridophytes in Kolli Hills, eastern Ghats of Tamil Nadu, India. J Nat Prod Plant Resour. 2011:1(2):50-5.

2. Wangchuk P, Tobgay T. Contributions of medicinal plants to the gross national happiness and biodiscovery in Bhutan. J Ethnobiol Ethnomed. 2015;11(48):2-12. https://doi.org/10.1186/s13002-015-0035-1.

3. Ferdousi $A$, Rahman MO, Hassan MA. Seed germination behaviour of six medicinal plants from Bangladesh. Bangl J Plant Taxon. 2014;21(1):71-6. 
4. Shah R, Islam M, Rabbi F, Shova NA, Akter A, Akter H, et al. Phytotherapeutic practices of a folk medicinal practitioner in Dinajpur district, Bangladesh. J Appl Pharm Sci. 2017;7(05):161-5.

5. Khatun M, Rahman M, Haque T, Rahman MM, Akter M, Akter S, Jhumur A. Cytotoxicity potentials of eleven Bangladeshi medicinal plants. Sci World J. 2014;2014:1-7.

6. Jarial R, Shard A, Thakur S, Sakinah M, Zularisam AW, Rezania S, et al. Characterization of flavonoids from fern Cheilanthes tenuifolia and evaluation of antioxidant, antimicrobial and anticancer activities. J King Saud Univ Sci. 2018;30(1):425-32.

7. Sen K. MukhopadhyayR. New report of vessel elements in Aleuritopteris and Cheilanthes. Taiwania. 2014;59(3):231-9.

8. Augustin N, Thomas B. Medico-potential ferns of Angamaly region, Ernakulam district, Kerala, India. IJCPCR. 2015;5(4):207-11.

9. Hanum F, Hamzah N. The use of medicinal plant species by the Temuan tribe of Ayer Hitam. Pertanika J Trop Agric Sci. 1999;22(2):85-94.

10. Benniamin A. Medicinal ferns of north eastern India with special reference to Arunachal Pradesh. Indian J Tradit Know. 2011;10(3):516-22.

11. Wagenen BCV, Larsen R, Cardellina JH, Ran D, Lidert ZC, Swithenbank C. Ulosantoin, a potent insecticide from the sponge Ulosaruetzleri. J Org Chem. 1993:58(2):335-7.

12. Senguttuvan J, Paulsamy S, Karthika K. Phytochemical analysis and evaluation of leaf and root parts of the medicinal herb, Hypochaeris radicata $L$. for in vitro antioxidant activities. Asian Pac J Trop Biomed. 2014;4(1):359-67.

13. Meena H, Pandey HK, Pandey P, Arya MC, Ahmed Z. Evaluation of antioxidant activity of two important memory enhancing medicinal plants Baccopa monnieri and Centella asiatica. Indian J Pharmacol. 2012;44(1):114-7.

14. Harbertson JF. Spayd. Measuring phenolics in the winery. Am J Enol Viticult. 2006;57(3):280-8

15. Jiao H, Wang SY. Correlation of antioxidant capacities to oxygen radical scavenging enzyme activities in blackberny. J Agric Food Chem. 2000;48(11):5672-6.

16. Bristy NJ, Hasan AN, Alam MN, Wahed TB, Roy P, Alam KK. Characterization of antioxidant and cytotoxic potential of methanolic extracts of different parts of Aegle marmelos (L.). Int J Pharm Sci Res. 2017;8(3):1476-84.

17. Brand-Williams W, Cuvelier ME, Berst C. Use of free radical method to evaluate antioxidant activity. LebensmWiss Technol. 1995;28:25-30.

18. Hussain F, Islam MA, Bulbul L, Moghal MR, Hossain MS. In vitro thrombolytic potential of root extracts of four medicinal plants available in Bangladesh. Anc Sci Life. 2014;33(3):162-4.

19. Omale J, Okafor PN. Comparative antioxidant capacity, membrane stabilization, polyphenol composition and cytotoxicity of the leaf and stem of Cissus multistriata. Afr J Biotechnol. 2008;7(17):3129-33.

20. Meyer BN, Ferringni NR, Puam JE, Lacobsen LB, Nichols DE. In vitro antibacterial, cytotoxic and free radical scavenging activities of an Aspergillus species. Drug Info J. 1982;31:516-54.

21. Coskun O. Separation techniques: chromatography. North Clin Istanbul. 2016;3(2):156-60

22. Danot $\mathrm{M}$, Nahmias $\mathrm{S}$, Zoller U. An undergraduate column chromatography experiment. J Chem Educ. 1984;61(11):1019.

23. Bajpai VK, Majumder R, Park JG. Isolation and purification of plant secondary metabolite using column chromatographic technique. Bangladesh J Pharmacol. 2016;11:844-8.

24. Chaturvedula VP, Prakash I. Isolation of Stigmasterol and $\beta$-Sitosterol from the dichloromethane extract of Rubus suavissimus. IntCurr Pharm J. 2012;1 (9):239-42.

25. Dhar KS, Wahed TB, Hasan AN, Wahed SB. In vitro antioxidant activities and cytotoxicity study of the methanolic extract of barks of Syzygium cymosum. Int J Pharm Sci Res. 2016;7(3):1021-5.

26. Hossain MI, Sakib MH, Mahmood AA, Karim N, Alam MS, Islam MA, Sharma M. Study on in-vitro thrombolytic activity of methanolic extract of Mesua ferrea leaves. Int J Med Health Res. 2015;1 (2):52-5.

27. Shahriar M, Khair NZ, Akhter R, Chowdhury SF. In vitro membrane stabilizing activity of Enythrina variegate bark. J Chem Pharm Res. 2015;7(4):960-2.

28. Sarah QS, Anny FC, Misbahuddin M. Brine shrimp lethality assay. Bangladesh J Pharmacol. 2017:12(2):5-9.

29. Prabha PS, Chaithanya KK, Hagos Z, Nagaraju B, Gopalakrishnan VK. Isolation and identification of bioactive compound from Ipomoea obscura (L.) Ker Gawl. J Pharm Res. 2017;11(1):10-4.

\section{Publisher's Note}

Springer Nature remains neutral with regard to jurisdictional claims in published maps and institutional affiliations.

\section{Submit your manuscript to a SpringerOpen ${ }^{\circ}$ journal and benefit from:}

- Convenient online submission

- Rigorous peer review

- Open access: articles freely available online

- High visibility within the field

- Retaining the copyright to your article

Submit your next manuscript at $\boldsymbol{\nabla}$ springeropen.com 